\title{
PENGARUH LIKUIDITAS, DER, FIRM SIZE DAN ASSET TURNOVER TERHADAP KINERJA KEUANGAN
}

\author{
Oleh : Puji Lestari \\ pujilestari5959@gmail.com \\ (Program Studi Akuntansi, FE Universitas Islam Batik Surakarta)
}

\begin{abstract}
Abstrak-Tujuan untuk mengetahui pengaruh likuiditas, struktur modal, firm size dan asset turnover terhadap kinerja keuangan. Metode penelitian yang digunakan adalah statistik deskriptif. Populasi pada penelitian ini adalah perusahaan makanan dan minuman pada Bursa Efek Indonesia pada 2015-2018. Teknik pengambilan sampel menggunakan metode purposive sampling dan mendapatkan sampel sebanyak 12 perusahaan dari beberapa kriteria. Sumber data adalah data sekunder. Metode analisis data menggunakan uji asumsi klasik dan analisis linear berganda menggunakan SPSS 21. Hasil penelitian ini menunjukkan bahwa struktur modal berpengaruh terhadap kinerja keuangan sebesar 15,8\%. Sementara likuiditas, firm size dan asset turnover tidak memiliki pengaruh terhadap kinerja keuangan. Dan 84,2\% dipengaruhi oleh faktor lain yang tidak diteliti dalam penelitian ini.
\end{abstract}

Kata Kunci : Kinerja Keuangan, Likuiditas, DER, Firm Size, Aset Turnover

Abstract- The aim is to determine the effect of liquidity, capital structure, firm size and asset turnover on financial performance. The research method used is descriptive statistics. The population in this study are food and beverage companies on the Indonesia Stock Exchange in 2015-2018. The sampling technique uses a purposive sampling method and gets a sample of 12 companies from several criteria. The data source is secondary data. The data analysis method uses the classic assumption test and multiple linear analysis using SPSS 21. The results of this study indicate that the capital structure influences financial performance by $15.8 \%$. While liquidity, firm size and asset turnover do not influence on financial performance. And $84.2 \%$ is influenced by other factors not examined in this study.

Keywords: Financial Performance, Liquidity, DER, Firm Size, Turnover Assets

\section{PENDAHULUAN}

Dalam dunia bisnis, perkembangan suatu usaha memiliki peran penting dalam keberlangsungan hidup perusahaan. Semakin banyak perusahaan yang muncul maka semakin banyak pula persaingan dalam dunia bisnis.
Untuk itu, diperlukannya keunggulan yang kompetitif agar mampu meningkatkan daya saing.

Selain meningkatkan daya saing agar lebih menarik minat masyarakat, perusahaan juga harus pandai dalam mengelola informasi mengenai kinerja perusahaan. 
Mengapa demikian, karena dari kinerja perusahaan tersebut dapat dilakukan evaluasi dari segala aktivitas perusahaan yang sedang berlangsung dari satu period eke periode selanjutnya.

Untuk itu diperlukannya kemampuan dalam melaksanakan kewajiban-kewajiban agar dapat mempertahankan keberlangsungan kegiatan operasional perusahaan. Salah satu indicator yang dapat digunakan untuk mengevaluasi kinerja perusahaan adalah ROA. ROA dapat digunakan untuk mengukur efektivitas perusahaan dalam memperoleh keuntungan. Semakin besar ROA maka menunjukkan bahwa kinerja perusahaan semakin baik serta ROA juga merupakan tolak ukur bagi investor.

Kinerja keuangan dipengaruhi oleh beberapa faktor. Pada penelitian Siti Nurlaela Bambang Mursito, Eny Kustiyah, Istiqomah, Sri Hartono (2019) berdasarkan hasil analisis dapat disimpulkan bahwa likuiditas secara simultan mempengaruhi kinerja keuangan (ROA). Sedangkan hasil penelitian Nyonita Ratna Sari, Musriha, dan Enny Istanti(2017) menunjukkan bahwa likuiditas tidak berpengaruh terhadap kinerja keuangan.

$$
\text { Penelitian Nasib (2019) }
$$

menujukkan hasil bahwa Firm Size (Ln Total Aset) secara simultan berpengaruh signifikan terhadap kinerja keuangan (ROA). Sedangkan penelitian Huang (2002) dan Talebria dkk (2010) menemukan bahwa Firm Size tidak memiliki pengaruh terhadap kinerja perusahaan.

Penelitian yang sama dilakukan oleh Nurlaela dkk (2019) hasil penelitian menunjukkan bahwa struktur modal (DER) memiliki pengaruh yang signifikan terhadap kinerja keuangan yang diukur dengan ROA. Sedangkan hasil yang berbeda ditemukan di Mwangi dan Birundu (2015) yang menunjukkan bahwa tidak ada hubungan yang signifikan antara struktur modal dengan ROA di UKM di Thika, Kenya.

Sedangkan Gunawan dan Alpi (2018) melakukan penelitian yang serupa dengan variabel berbeda hasil penelitian menunjukkan bahwa Asset Turnover berpengaruh signifikan terhadap ROA. Berbeda hasil pada penelitian Ega Iskarisma (2017) yang menunjukkan hasil Asset Turnover tidak berpengaruh terhadap ROA.

Berdasarkan latar belakang di atas, peneliti bertujuan untuk melakukan penelitian dengan judul "Pengaruh Likuiditas, DER, Firm Size dan Asset Turnover Terhadap Kinerja Keuangan"

\section{METODE PENELITIAN}

Penelitian ini bertujuan untuk meneliti pengaruh Likuiditas, DER, Firm Size dan Asset Turnover terhadap kinerja keuangan pada perusahaan makanan dan minuman yang terdaftar di Bursa Efek Indonesia tahun 2015-2018. Jenis 
Penelitian ini adalah penelitian sekunder. Populasi dalam penelitian 12 Perusahaan, dengan sampel 48 perusahaan menggunakan metode purposive sampling. Metode analisis data dalam penelitian ini adalah statistik deskriptif, uji asumsi klasik, dan analisis regresi linear berganda.

1. Variabel Dependen

a. Kinerja Keuangan

Kinerja

keuangan merefleksikan kinerja fundamental perusahaan.

$$
R O A=\frac{\text { laba bersih }}{\text { total aset }}
$$

2. Variabel Independen

a. Likuiditas

Kemampuan dalam menjual suatu asset guna mendapatkan kas pada waktu yang singkat.

likuiditas $=\frac{\text { aset lancar }}{\text { hutang lancar }}$

b. DER

Perimbangan jumlah utang jangka pendek yang bersifat tetap, hutang jangka panjang, saham preferen dan saham biasa.

$$
D E R=\frac{\text { Total hutang }}{\text { total ekuitas }}
$$

c. Firm Size

Penjumlahan aktiva lancar dan aktiva tetap yang merupakan harta perusahaan secara keseluruhan.

d. Asset Turnover

Rasio yang menggambarkan perputaran aktiva diukur dengan volume penjualan.

Aset turnover $=\frac{\text { penjualan }}{\text { total aset }}$

\section{HASIL DAN PEMBAHASAN}

\section{Uji Statistik Deskriptif}

Analisis statistik deskriptif untuk melihat gambaran secara umum dari data yang didapatkan pada penelitian. Pada penelitian ini pengukurannya memusatkan pada nilai minimum, maximum, mean dan standar deviasi masing-masing variabel.

Tabel 1. Uji Statistik Deskriptif

\begin{tabular}{|lccccc|}
\hline & N & Minimum & Maximum & Mean & Std. Deviation \\
\hline ROA & 48 & 0.01 & 0.53 & 0.1180 & 0.10626 \\
LIKUIDITAS & 48 & 0.00 & 5.11 & 1.6376 & 1.38733 \\
DER & 48 & 0.06 & 1.74 & 0.7693 & 0.46135 \\
FIRM_SIZE & 48 & 20.90 & 32.20 & 28.5452 & 2.42414 \\
ASSET_TURNOVER & 48 & 0.13 & 3.11 & 1.3152 & 0.64348 \\
Valid N (listwise) & 48 & & & & \\
\hline
\end{tabular}

Sumbe: Data SPSS 21 


\section{Uji Asumsi Klasik}

Uji asumsi klasik dilakukan melalui beberapa tahap dan beberapa macam uji. Pengujian tersebut meliputi uji normalitas, uji normalitas, uji multikolinearitas, uji autokorelasi dan uji heteroskedastisitas.

Tabel 2. Uji Normalitas

\begin{tabular}{|l|c|lr|}
\hline & $\begin{array}{c}\text { Unstandardized } \\
\text { Residual }\end{array}$ & Syarat & Kesimpulan \\
\hline Asymp. Sig. (2-tailed) & 0.154 & $\begin{array}{l}>0,05 \\
\text { Normal }\end{array}$ & Data Terdistribusi \\
\hline
\end{tabular}

Sumbe: Data SPSS 21

Dari tabel 2 dapat diketahui bahwa nilai signifikasi Kolmogrov Smirnov (K-S) adalah 0,154, artinya bahwa nilai tersebut lebih besar dari 0,05 yang berarti data terdistribusi normal.

Tabel 3. Uji Multikolinearitas

\begin{tabular}{|c|c|c|c|c|c|}
\hline Variabel & Tolerance & Std & VIF & Std & Keterangan \\
\hline Likuiditas & 0,777 & $>0,10$ & 1,287 & $<10$ & $\begin{array}{c}\text { Tidak terjadi } \\
\text { Multikolinieritas }\end{array}$ \\
\hline DER & 0,772 & $>0,10$ & 1,295 & $<10$ & $\begin{array}{c}\text { Tidak terjadi } \\
\text { Multikolinieritas }\end{array}$ \\
\hline Firm Size & 0,866 & $>0,10$ & 1,155 & $<10$ & $\begin{array}{c}\text { Tidak terjadi } \\
\text { Multikolinieritas }\end{array}$ \\
\hline $\begin{array}{c}\text { Asset } \\
\text { Turnover }\end{array}$ & 0,920 & $>0,10$ & 1,086 & $<10$ & $\begin{array}{c}\text { Tidak terjadi } \\
\text { Multikolinieritas }\end{array}$ \\
\hline
\end{tabular}

Sumber: Data SPSS 21

Berdasarkan hasil uji multikolinearitas pada tabel 3 dapat diketahui bahwa variabel Likuiditas, DER, Firm Size, dan Asset Turnover memiliki nilai tolerance $>0,1$ dan nilai VIF <10, maka dapat disimpulkan bahwa semua variabel tidak terjadi multikolinearitas.

$$
\text { Berdasarkan hasil uji }
$$
heteroskedastisitas pada tabel 3 di bawah menunjukkan bahwa variabel likuiditas, DER, firm size dan asset turnover memiliki nilai signifikansi > 0,05 , maka dapat disimpulkan bahwa tidak terjadi heteroskedastisitas dalam model ini. 
Tabel 4. Uji Heteroskedastisitas

\begin{tabular}{|l|c|c|c|}
\hline \multicolumn{1}{|c|}{ Variabel } & Sig & Syarat & Kesimpulan \\
\hline Likuiditas & 0,105 & $>0,05$ & $\begin{array}{c}\text { Tidak Terjadi } \\
\text { Heteroskedastisitas } \\
\text { DER }\end{array}$ \\
Firm Size & 0,812 & $>0,05$ & $\begin{array}{c}\text { Tidak Terjadi } \\
\text { Heteroskedastisitas } \\
\text { Tidak Terjadi }\end{array}$ \\
Asset Turnover & 0,355 & $>0,05$ & $\begin{array}{c}\text { Heteroskedastisitas } \\
\text { Tidak Terjadi } \\
\text { Heteroskedastisitas }\end{array}$ \\
\hline
\end{tabular}

Sumber: Data SPSS 21

Tabel 5. Uji Autokorelasi

\begin{tabular}{|c|c|c|c|}
\hline DU & < Durbin Watson & $<$ 4-DU & Keterangan \\
\hline 1.670 & $<1.938$ & $<2.330$ & Tidak Terjadi Autokorelasi \\
\hline
\end{tabular}

Sumber: Data SPSS 21

Hasil dari olah data pada tabel 5 di atas dapat kita lihat bahwa nilai Durbin-Watson sebesar 1.938. Karena nilai DW terletak diantara DU dan 4-DU $(1.670<1.938<2.330)$.
Maka dapat disimpulkan bahwa pada penelitian ini dinyatakan bebas dalam uji autokorelasinya atau tidak ada autokorelasi.

Tabel 6. Uji Analisis Regresi Linear Berganda

\begin{tabular}{|c|c|}
\hline Variabel & B \\
\hline Constant & 0,327 \\
Likuiditas & $-0,016$ \\
DER & $-0,085$ \\
Firm Size & $-0,004$ \\
Asset Turnover & 0,006 \\
\hline
\end{tabular}

Sumber: Data SPSS 21

Berdasarkan hasil pengujian diatas, maka didapat persamaan regresi sebagai berikut:

$\mathrm{Y}=0,327-0,016 \mathrm{X}_{1}-0,085 \mathrm{X}_{2}-0,004 \mathrm{X}_{3}+0,006 \mathrm{X}_{4}+\mathrm{e}$ Persamaan regresi linier berganda yang telah terbentuk tersebut diatas mempunyai pengertian sebagai berikut : a. Konstanta yang diperoleh sebesar 0,327 menyatakan bahwa jika semua variabel independen bernilai 1 persen, maka kinerja keuangan akan naik sebesar 0,327 atau $32,7 \%$. 
b. Koefisien Regresi Variabel Likuiditas bernilai -0,016. Hal ini berarti apabila variabel likuiditas naik sebesar 1 persen dengan asumsi variabel yang lainnya tetap, maka diikuti penurunan likuiditas sebesar -0,016 atau $1,6 \%$.

c. Koefisien Regresi Variabel DER bernilai $-0,085$. Hal ini berarti apabila variabel DER naik sebesar 1 persen dengan asumsi variabel yang lainnya tetap, maka diikuti penurunan DER sebesar -0,085 atau $8,5 \%$.

d. Koefisien Regresi Variabel Firm Size bernilai -0.004 hal ini berarti apabila firm size naik sebesar 1 persen dengan asumsi variabel yang lainnya tetap, maka diikuti penurunan firm size sebesar -0,004 atau $0,4 \%$.

e. Koefisien Regresi Variabel Asset Turnover bernilai 0,006. Hal ini berarti apabila asset turnover naik sebesar 1 persen dengan asumsi variabel yang lainnya tetap, maka diikuti kenaikan asset turnover sebesar 0,006 atau $0,6 \%$.

Berdasarkan pada tabel 7 di bawah diperoleh $\mathrm{F}$ hitung sebesar $2,020<\mathrm{F}$ tabel sebesar 2,589 dan signifikansi sebesar $0,109>0,05$ sehingga terlihat bahwa nilai signifikansi tersebut lebih besar dari 0,05 . Hal ini menunjukkan bahwa variabel independen signifikansi secara bersama-sama tidak berpengaruh terhadap variabel dependen.

Tabel 7. Uji Kelayakan Model

\begin{tabular}{|c|c|c|c|c|c|}
\hline Hipotesis & Fhitung & F table & Sig & Syarat & Keputusan \\
\hline $\mathrm{Ha}$ & 2,020 & 2,589 & 0,109 & $<0,05$ & Simultan \\
\hline
\end{tabular}

Sumber: Data SPSS 21

Tabel 8. Uji Hipotesis

\begin{tabular}{|c|c|c|c|c|c|}
\hline Hipotesis & T Hitung & T tabel & Sig & Syarat & Kesimpulan \\
\hline $\mathrm{H}_{1}$ & $-1,341$ & 2,017 & 0,187 & $<0,05$ & Ditolak \\
$\mathrm{H}_{2}$ & -2.324 & 2,017 & 0,025 & $<0,05$ & Diterima \\
$\mathrm{H}_{3}$ & $-0,657$ & 2,017 & 0,514 & $<0,05$ & Ditolak \\
$\mathrm{H}_{4}$ & 0,230 & 2,017 & 0,819 & $<0,05$ & Ditolak \\
\hline
\end{tabular}

Sumber: Data SPSS 21

Berdasarkan tabel 8 di atas maka uji hipotesis sebagai berikut:

\section{$\mathrm{H}_{1}$ : Likuiditas berpengaruh terhadap kinerja keuangan}


Berdasarkan hasil pengujian uji $\mathrm{t}$ diperoleh $\mathrm{t}$ hitung untuk variabel Likuiditas sebesar -1,341 yang artinya $\mathrm{t}$ hitung $<\mathrm{t}$ tabel $(-1,341<$ $2,017)$ dan nilai signifikansi sebesar 0,187 yang artinya nilai signifikansi $>0,05(0,187>0,05)$ maka ditarik kesimpulan bahwa likuiditas tidak berpengaruh signifikan terhadap kinerja keuangan. Hasil penelitian ini menunjukkan bahwa likuiditas tidak berpengaruh signifikan terhadap kinerja keuangan sehingga dapat disimpulkan bahwa $\mathrm{H}_{0}$ diterima dan $\mathrm{H}_{1}$ ditolak.

\section{$\mathrm{H}_{2}$ : Pengaruh DER terhadap kinerja keuangan}

Berdasarkan hasil pengujian uji $\mathrm{t}$ diperoleh $\mathrm{t}$ hitung untuk variabel DER sebesar $-2,324$ yang artinya $t$ hitung > t tabel $(-2,324>2,017)$ dan nilai signifikansi sebesar 0,025 yang artinya nilai signifikansi $<0,05$ $(0,025<0,05)$ maka ditarik kesimpulan bahwa DER berpengaruh negative dan signifikansi terhadap kinerja keuangan.

Hasil penelitian menunjukkan bahwa DER berpengaruh negative dan signifikan terhadap struktur modal sehingga disimpulkan bahwa $\mathrm{H}_{0}$ ditolak dan $\mathrm{H}_{2}$ diterima.

\section{$\mathrm{H}_{3}$ : Firm Size berpengaruh terhadap kinerja keuangan}

Berdasarkan hasil pengujian uji $\mathrm{t}$ diperoleh $\mathrm{t}$ hitung untuk variabel Firm size sebesar -0,657 yang artinya $\mathrm{t}$ hitung $<\mathrm{t}$ tabel $(-0,657<2,017)$ dan nilai signifikansi sebesar 0,514 yang artinya nilai signifikansi $>0,05$ $(0,514>0,05)$ maka ditarik kesimpulan bahwa firm size tidak berpengaruh dan signifikan terhadap kinerja keuangan. Hasil penelitian menunjukkan bahwa firm size tidak berpengaruh dan signifikan terhadap kinerja keuangan sehingga disimpulkan bahwa $\mathrm{H}_{0}$ diterima dan $\mathrm{H}_{3}$ ditolak.

\section{$\mathrm{H}_{4}$ : Asset Turnover berpengaruh terhadap kinerja keuangan \\ Berdasarkan hasil pengujian uji} $\mathrm{t}$ diperoleh $\mathrm{t}$ hitung untuk variabel asset turnover sebesar 0,230 yang artinya $\mathrm{t}$ hitung $<\mathrm{t}$ tabel $(0,230<$ 2,017) dan nilai signifikansi sebesar 0,819 artinya nilai signifikansi $<0,05$ $(0,819<0,05)$ maka ditarik kesimpulan bahwa asset turnover tidak berpengaruh signifikan terhadap kinerja keuangan.

Hasil penelitian bahwa asset turnover tidak berpengaruh signifikan terhadap kinerja keuangan sehingga disimpulkan bahwa $\mathrm{H}_{0}$ diterima dan $\mathrm{H}_{4}$ ditolak.

Tabel 9. Uji Koefisien Determinasi

\begin{tabular}{|l|l|}
\hline $\begin{array}{c}\text { Adjusted R } \\
\text { Square }\end{array}$ & \multicolumn{1}{|c|}{ Kesimpulan } \\
\hline 0,158 & $\begin{array}{l}\text { Berpengaruh } \\
\text { sebesar } 15,8 \%\end{array}$ \\
\hline
\end{tabular}

Sumber: Data SPSS 21

Dari tabel 9 di atas dapat diperoleh nilai adjust $R^{2} \quad 15,8 \%$ sehingga dapat disimpulkan bahwa 
variabel Likuiditas (X1), DER (X2), Firm Size (X3), dan Asset Turnover (X4) mempengaruhi kinerja keuangan (Y) sebesar 15,8\% dan $84,2 \%$ dipengaruhi oleh faktor lain yang tidak diteliti dalam penelitian ini. Dengan demikian maka dapat disimpulkan bahwa keberadaan variabel kinerja keuangan dapat memperlemah atau menurunkan pengaruh variabel Independen terhadap variabel dependen.

\section{KESIMPULAN}

Penelitian ini betujuan untuk menguji pengaruh likuiditas, DER, firm size dan Asset Turnover terhadap kinerja keuangan. Penelitian ini menggunakan 12 perusahaan sector makanan dan minuman yang terdaftar di BEI periode tahun 20152018. Penentuan sampel ini menggunakan purposive sampling dengan kriteria dan ketentuan tertentu. Berdasarkan hasil analisis menunjukkan bahwa variabel likuiditas tidak berpengaruh terhadap kinerja keuangan, hasil penelitian ini didukung oleh (Puteri Qoniah Dayu, 2015) bahwa likuiditas tidak berpengaruh signifikansi terhadap kinerja keuangan.

Berdasarkan hasil penelitian menunjukkan bahwa DER berpengaruh terhadap kinerja keuangan, hasil penelitian ini didukung oleh Yoyo Sudaryo dan Ika Yanuar Pratiwi (2016) bahwa terdapat pengaruh antara DER dan kinerja keuangan.
Berdasarkan hasil penelitian menunjukkan bahwa Firm Size tidak berpengaruh terhadap kinerja keuangan, hasil penelitian ini didukung oleh Alfi Churniawati, Kartika Hendra Titisari dan Anita Wijayanti (2019), bahwa firm size tidak memiliki pengaruh terhadap kinerja keuangan.

Berdasarkan hasil penelitian menunjukkan bahwa Asset Turnover tidak berpengaruh terhadap kinerja keuangan, hasil penelitian ini didukung oleh Sanjaya, Sudirman, dan Dewi (2015) yang menyatakan bahwa variabel asset Turnover menunjukkan tidak berpengaruh terhadap kinerja keuangan.

\section{SARAN}

Berdasarkan kesimpulan dan keterbatasan pada penelitian ini, maka dapat disimpaikan beberapa saran sebagai berikut :

a. Bagi peneliti selanjutnya diharapkan dapat menambah populasi tidak hanya pada sektor makanan dan minuman dan masa periode yang lebih lama agar memperkuat hasil penelitian.

b. Bagi peneliti selanjutnya diharapkan dapat menambah variabel-variabel lain agar dapat memperkuat hasil penelitian.

\section{DAFTAR PUSTAKA}

Abbas, D. S. (2018). Pengaruh Current Ratio, Account Receivable Turnover, Inventory Turnover, Total Asset Turnover dan Debt To 
Equity terhadap Return on Asset (Pada Perusahaan Sub Sektor Otomotif dan Komponen yang Terdaftar di Bursa Efek Indonesia Periode 2011-2014). UMT Journal Management System, Vol 2 No 1. Hal 55-72. http://jurnal.umt.ac.id/index.p $\mathrm{hp} /$ competitive/article/view/4 65

Azis, A., \& Hartono, S.E., M.Si, D. (2017). Pengaruh Good Corporate Governance, Struktur Modal, Dan Leverage Terhadap Kinerja Keuangan Perusahaan Pada Sektor Pertambangan Yang Terdaftar Di Bursa Efek Indonesia Tahun 2011-2015. Jurnal lmu Manajemen, Vol 5 No 3. Hal 1-13. http://jurnalmahasiswa.unesa. ac.id/index.php/jim/article/vie w/20396/18569

Churniawati, A., Titisari, K. H., \& Wijayanti, A. (2019). Pengaruh Good Corporate Governance,Leverage, dan Firm Size Terhadap Kinerja Keuangan. Online Journal Systems, Vol 2 No 1. http://openjournal.unpam.ac.i $\mathrm{d} /$ index.php/SNU/article/view 12629

Dewi, D. S., Susbiyani, A., \& Syahfrudin, A. (2019). Pengaruh Penerapan Good Corporate Governance, Total Asset Turn Over dan Kepemilikan Institusional Terhadap Kinerja Keuangan Perusahaan . International Journal of Social Science and Business, Vol 3 No 4. Hal 473-480. https://www.researchgate.net/ publication/337652366_Peng aruh_Penerapan_Good_Corp orate_Governance_Total_Ass et_Turn_Over_dan_Kepemili kan_Institusional_Terhadap_ Kinerja_Keuangan_Perusaha an

Gunawan, A., \& Alpi, M. F. (2018). Pengaruh Curent Rasio dan Total Asset Turnover terhadap Return on Assets pada Perusahaan Plastik dan Kemasan. Jurnal Riset A, Vol 7 no 2. Hal 1-36. http://aksioma.unram.ac.id/in dex.php/aksioma/article/view 143

Hartoyo. (2018). Hubungan Current Ratio, Struktur Modal, dan Ukuran Perusahaan terhadap Kinerja Keuangan Perusahaan Pertambangan yang Terdaftar di BEI Periode 2014-2016. Jurnal Maksipreneur. Hal 81-97. https://www.researchgate.net/ publication/329678249_Hubu ngan_Current_Ratio_Struktur _Modal_dan_Ukuran_Perusa haan_terhadap_Kinerja_Keua ngan_Perusahaan_Pertamban gan_yang_Terdaftar_di_BEI_ Periode_2014-2016

Isbanah, Y. (2015). Pengaruh ESOP, Leverage dan Ukuran Perusahaan terhadap Kinerja Keuangan Perusahaan di BEI. jurnal riset ekonomi dan manajemen. Hal 28-41. http://jrem.iseisby.or.id/index .php/id/article/view/6/pdf

Kong, Yusheng \& Musah, M. (2019). The Effect of Liquidity and Capital Structure on The Financial 
Performance of Firm Listed on The Ghana Alternative Market (GAX).International Journal of Reserch in Economics and Sosial Sciences(IJRESS). Vol 8. Hal 74-92.

https://www.researchgate.net/ publication/333055596_The Effect_Of_Liquidity_And_Ca pital_Structure_On_The_Fina ncial_Performance_Of_Firms _Listed_On_The_Ghana_Alt ernative_Market_Gax

Laela, R. H., \& Hendratno. (2019). Pengaruh Current Ratio, Debt To Equity Ratio Dan Total Asset Turnover Terhadap Return On Asset . Jurnal Akuntansi, Audit dan Sistem Informasi Akuntansi, Vol 3 No 1. Hal 120-131. https://www.neliti.com/id/pub lications/284420/apengaruhcurrent-ratio-debt-to-equityratio-dan-total-asset-turnoverterhadap-r

Nasib, \& Azzahra, Suci, An. (2019). Pengaruh Firm Size dan Leverage Ratio Terhadap Kinerja Keuangan Pada Perusahaan Pertambangan. JWEM STIE Mikroskil.Vol 9 No 1. Hal 13-20. https://www.mikroskil.ac.id/e jurnal/index.php/jwem/article /view/588/283

Nurlaela, S., Mursito, B., Kustiyah, E., Istiqomah, \& Hartono, S. (2019). Asset Turnover, Capital Structure and Financial Performance Consumption Industry Company in Indonesia Stock Exchange. International Journal of Economics and
Financial Issues. Vol 9 No 3.

Hal 297-301. https://www.researchgate.net/ publication/334100090_Asset _Turnover_Capital_Structure _and_Financial_Performance _Consumption_Industry_Co mpany_in_Indonesia_Stock_ Exchange

Sudaryo, Y., \& Pratiwi, I. Y. (2016). Pengaruh Struktur Modal Dan Likuiditas Terhadap Profitabilitas Dan Dampaknya Terhadap Kinerja Keuangan . Jurnal Indonesia Membangun, Vol 5 No https://jurnal.inaba.ac.id/inde x.php/JIM/article/view/58/53 